\title{
UHL'S ANOMALY: A RARE CAUSE OF CARDIOMEGALY
}

\author{
Ulaş KARADAŞ ${ }^{1}$, Ali Rahmi BAKILER ${ }^{1}$, Kayı ELIAÇIK ${ }^{1}$, Dilek ÇAVUŞOĞLU1 ${ }^{1}$, Zülal ÜLGER ${ }^{2}$
}

\author{
${ }^{1} 1$ Clinics of Paediatrics, Tepecik Training \\ and Research Hospital, Izmir, Turkey \\ ${ }^{2}$ Department of Paediatric Cardiology \\ Egean University School of Medicine \\ Izmir, Turkey \\ Corresponding author: \\ Kayı Eliaçık \\ Clinics of Pediatrics \\ Yenişehir, İzmir, Turkey \\ kayieliacik@gmail.com \\ Tel.: + $02324696969 / 3460$ \\ Fax.: + 902324330756
}

Received: December 3, 2013

Accepted: May 22, 2014

Copyright (C) 2014 by University Clinical Centre Tuzla. E-mail for permission to publish: paediatricstoday@ukctuzla.ba

\begin{abstract}
Objective - Uhl's anomaly, a very rare anomaly with unknown aetiology, is characterized by congenital hypoplasia of the right ventricular myocardium. In this paper, we aim to discuss the clinical findings and the imagining methods. Case report - A six-month-old case was referred us for cardiomegaly. Echocardiography showed a hugely dilated and diffuse hypokinetic right ventricle, magnetic resonance images and cardiac catheterization proved the diagnosis of Uhl's anomaly. Conclusion - Uhl's anomaly is a rare cause of cardiomegaly, and echocardiography and cardiac MR images are beneficial in the diagnostic process of this anomaly.
\end{abstract}

Key words: Uhl's anomaly - Cardiomegaly.

\section{Introduction}

Uhl's anomaly of the right ventricle is an unusual cardiac disorder with the almost complete absence of the right ventricular myocardium, normal tricuspid valve, and preserved septal and left ventricular myocardium $(1,2)$. The pathogenesis of this anomaly is still unclear, however, it is supposed that the cause is the uncontrolled and selective apoptosis of the right ventricle $(1,3)$. Characteristically, the severe form presents in infancy with intractable congestive cardiac failure. The hemodynamic findings reflect right ventricular failure, and the right atrium is responsible for maintaining the pulmonary circulation. Cyanosis may be present, resulting from a right-to-left shunt at the atrial level $(3,4)$.
In this paper, we present a case of Uhl's anomaly referred us due to cardiomegaly.

\section{Case report}

A six-month-old female infant being monitored for pulmonary infection was referred to us due to cardiomegaly detected on chest radiography. On physical examination, her weight and length were $<3$ percentiles. Her cardiac auscultation revealed a proto-mesosystolic murmur on the right sternal border (3/6 on Levine's scale) and cardiac failure. An electrocardiogram showed sinus rhythm with a heart rate of 150 beats per minute, QRSaxis: $+150^{\circ}$ on the frontal plane, right atrial enlargement, and low QRS amplitude in the right precordial leads (Fig. 1). 


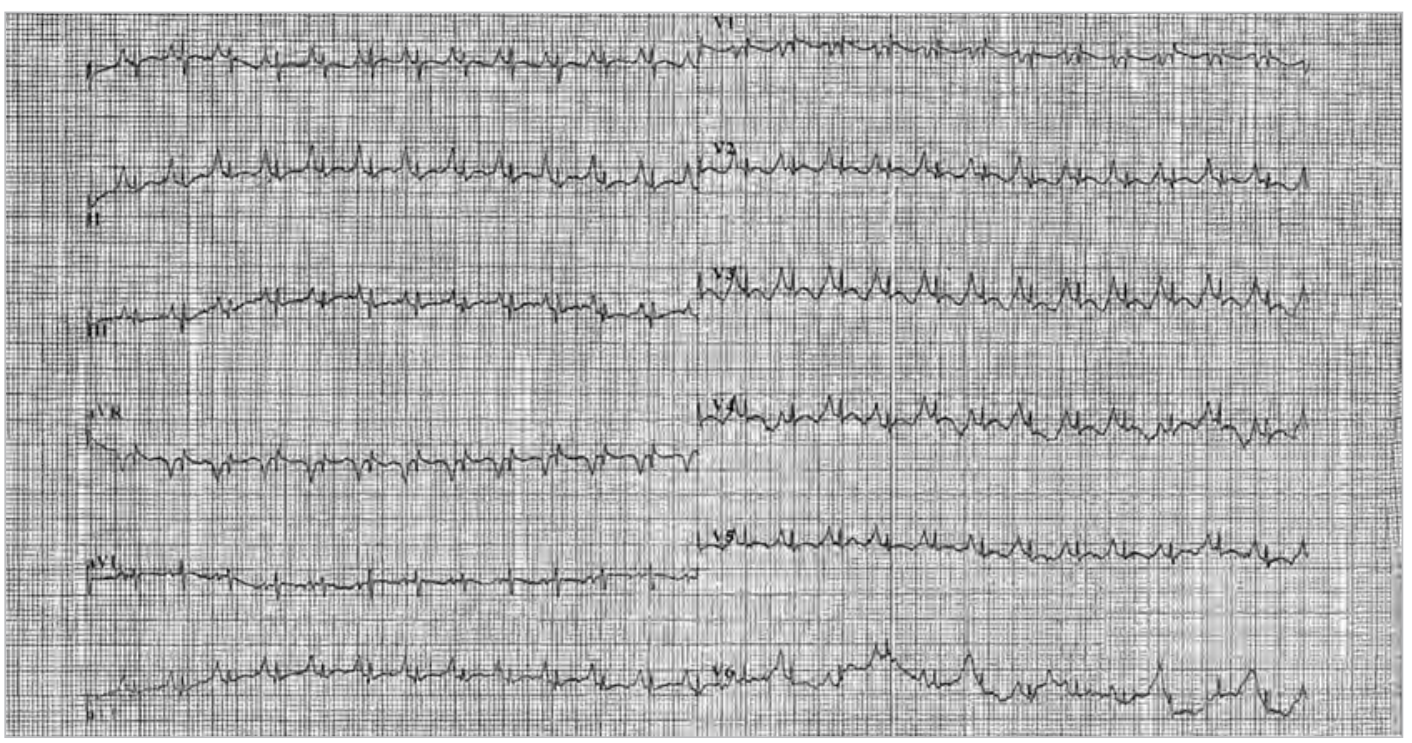

Fig. 1 Right atrial enlargement signs and low QRS amplitude in electrocardiogram.

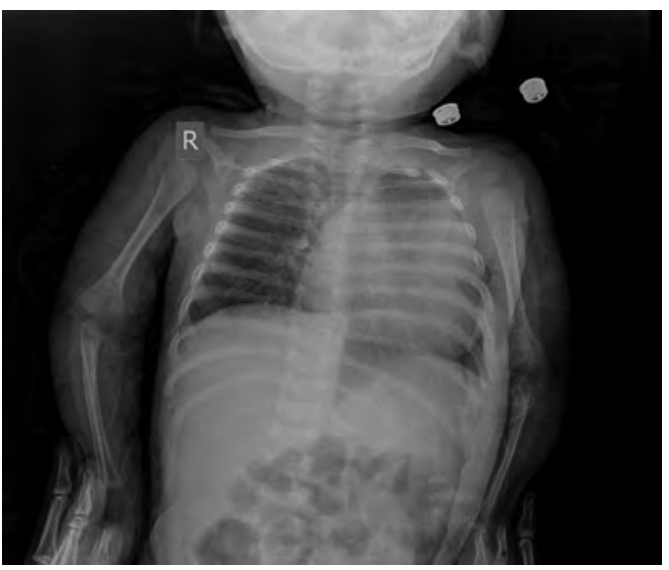

Fig. 2 Marked cardiomegaly and significant pulmonary vascular vessels in X-ray.

Chest X-ray showed marked cardiomegaly and significantly enlarged pulmonary vascular vessels (Fig. 2).

Echocardiography showed a significant tricuspid insufficiency, with marked dilatation of the right ventricle with diffuse hypokinesis. The myocardium of the right ventricle was absent, however the interventricular septum, and the left ventricle myocardium were normal (Fig. 3a, 3b).

The pulmonary arterial and pulmonary venous flow were also normal, and the left and right ventricular end-diastolic diameters were 20 and $40 \mathrm{~mm}$ respectively. The left ventricular ejection fraction was $72 \%$ and fractional shortage was $40 \%$.

The magnetic resonance images depict a clear reduction in the thickness of the right ventricular wall, with the almost complete absence of the right ventricular free wall myocardium, with a paucity of apical trabeculations, and normal left ventricular myocardium and interventricular septum (Fig. 4).

Diagnostic cardiac catheterization confirmed the marked dilatation of the right atrium and ventricle, together with severe tricuspid insufficiency. Manometry showed a mean pressure of $18 \mathrm{mmHg}$. Cardiac catheterization also showed an enlarged right atrium and ventricle, a thin wall structure, and the weak contraction of this ventricle. The patient was then followed up periodically in our clinic. In her clinical evaluation at 1 year of age, the child was asymptomatic, weighed $6 \mathrm{~kg}$, and her condition was stable. Aceytlsalicylic acid therapy was begun to avoid major thromboembolism. An operation bypassing the right ventricle was planned, however the parents did not give permission for the 


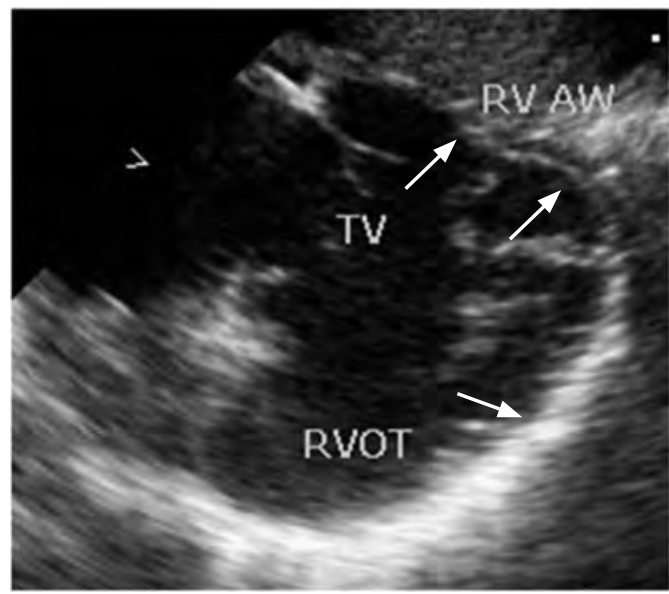

Fig. 3a Enlarged right ventricle and the absence of right ventricle myocardium in echocardiography, subcostal short-axis views.

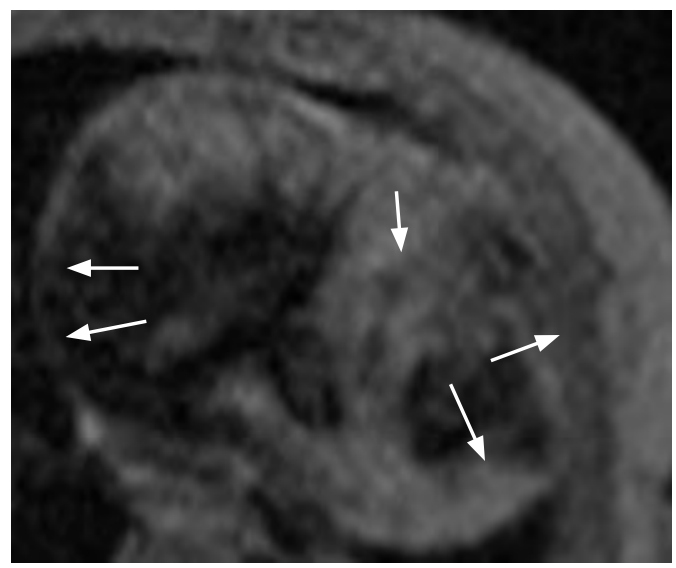

Fig. 4. Paucity of apical trabeculations in the right ventricular free wall with normal left ventricular myocardium and interventricular septum in magnetic resonance images.

operation. During the follow-up the patient lived to 2 years of age, but then died of cardiac failure.

\section{Discussion}

In 1905, Osler was the first to report a heart with a very thin wall similar to parchment. In 1949, Uhl reported his first case after performing an autopsy on an 8-month-old infant. There are several hypotheses about the

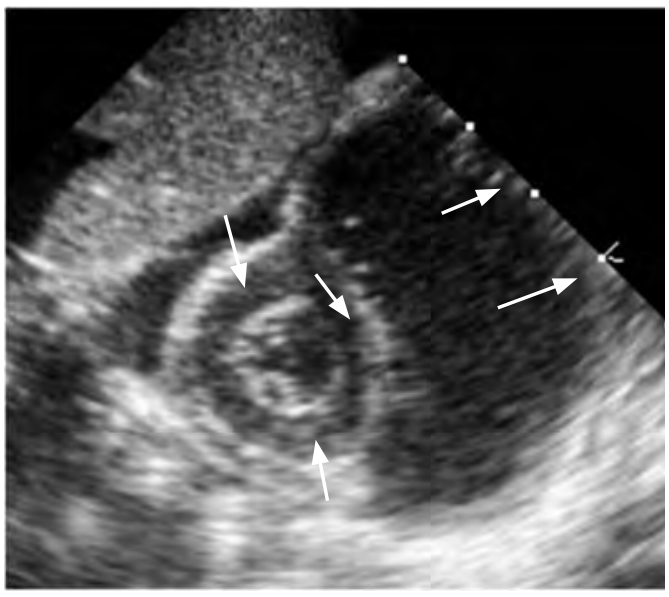

Fig. 3b Marked dilatation of the right ventricle with normal left ventricular myocardium and interventricular septum on echocardiography, subcostal short-axis views.

pathogenesis of Uhl's anomaly and it is still unclear. However the latest molecular studies have clarified the fact that selective apoptosis occurs in the myocytes of the right myocardium. Despite several reports, a reasonable explanation for the absence of myocardium in the right ventricle is still lacking. A failure in development during embryonic life is a possible cause $(5,6)$.

Uhl's anomaly is only one of many causes of right ventricular dilatation, including Ebstein's disease, partial anomalous venous return, absence of the pericardium, pulmonary atresia, aortic coarctation or aortic interruption, and right ventricular arrhythmogenic dysplasia $(4,7)$. In the review by Gerlis et al. (7), the authors concluded that many cases that would now be described as right ventricular arrhythmogenic dysplasia were previously termed "Uhl's anomaly". Uhl's anomaly has morphological features, such as complete absence of the myocardium in the right ventricular parietal wall, which is composed of the endocardium and epicardium, with no interposition of adipose tissue between these layers. On the other hand, there is localised adipose tissue between these layers within the 
right ventricular arrhythmogenic dysplasia, and more than half the cases have family histories with biventricular involvement. In our case, the infant had no familial antecedents of Uhl's anomaly, which may be seen in right ventricular arrhythmogenic dysplasia.

The male sex predominates in Uhl's anomaly and in arrhythmogenic dysplasia with an incidence of $56 \%$ and $70 \%$, respectively. The differential diagnosis for right ventricular arrhythmogenic dysplasia was made on the bases of the female sex, absence of family history, no adipose tissue observed between the layers of the endocardium and epicardium, and the complete absence of myocardium, and there was no arrhythmia. The major clinical finding in Uhl's anomaly is heart failure, as in our infant's case. Based on these findings, the differential diagnosis was established as right ventricular arrhythmogenic dysplasia.

In the past, the diagnosis of Uhl's anomaly was usually made on autopsy, but today, with the progress of ECHO and MRI, an early diagnosis is possible (5). Cardiac catheterisation may be harmful in Uhl's anomaly (4). On cardiac MRI, as in our case, the absence of myocardium and adipose tissue, an enlarged right ventricular cavity with reduced apical trabeculation in the free right ventricle wall, right atrium hypertrophy and normal left ventricle myocardium, may be detected (5).

Uhl's anomaly has a poor prognosis, but patients with partial absence of the right ventricular myocardium and no associated lesions may reach adulthood $(2,8)$. The most interesting case in the literature was a 41-year-old woman with Uhl's anomaly, who had had six successful consecutive deliveries (9).

Operations bypassing the right heart (subtotal right ventricle free wall resection, tricuspid valve repair and one and one-half ventricle repair (1)), in addition to cardiac transplantation, offer more effective and promising results in the treatment of Uhl's anomaly (10). However, high-risk clot formation in the RV and occurrence of embolization are thought to be much more common in surgery bypassing the right side of the heart (especially, bidirectional Glenn shunt, and one-and-a-half ventricle repair). Hoschtitzky et al. (11) described an operation for surgical exclusion of the right ventricle to reduce the detrimental effects of ventricular distension and ventriculo-ventricular interaction from septal shift toward the left. Our case was also admitted with cardiac failure symptoms, such as frequent breathing and poor sucking. Alongside cardiac failure therapy, an operation bypassing the right heart was planned, however the parents did not give their consent due to the high mortality risk. In the 15th month of the follow-up period our patient died.

\section{Conclusion}

As a result, we conclude that Uhl's anomaly should be considered as a rare cause of cardiomegaly, with the emphasis on the benefits and importance of echocardiography and cardiac MR images in the diagnostic process of this anomaly. It should be kept in mind that if the operation is not performed at the right time, Uhl's anomaly rapidly becomes mortal.

Authors' contributions: Conception and design: UK, $\mathrm{ARB}$ and KE; Acquisition, analysis and interpretation of data: UK, ARB, KE, DÇ and ZÜ; Drafting the article UK, KE and DÇ; Revising it critically for important intellectual content: ARB, DÇ and ZÜ.

Conflict of interest: The authors declare that they have no conflict of interest.

\section{References}

1. Greer ML, MacDonald C, Adatia I. MRI of Uhl's Anomaly. Circulation. 2000;101;230-2.

2. Epstein ML. Uhl Anomaly. Allen HD, Driscoll DJ, Shaddy RE, Feltes TF, eds. Moss and Adams' Heart 
Disease in Infants, Children and Adolescents. 7th Edition. Philadelphia: Lippincott Williams and Wilkins; 2008. p. 832.

3. Hoback J, Adicoff A, From AH, Smith M, Shafer $\mathrm{R}$, Chesler E. A report of Uhl's disease in identical adult twins: evaluation of right ventricular dysfunction with echocardiography and nuclear angiography. Chest. 1981;79;306-10.

4. Cheng JF, Mohammed TL, Griffith BP, White CS. CT of Uhl's anomaly in an adult. Int J Cardiovasc Imaging. 2005;21:663-6.

5. Ikari NM, Azeka E, Aiello VD, Atik E, BarberoMarcial M, Ebaid M. Uhl's anomaly. Differential diagnosis and indication for cardiac transplantation in an infant. Arq Bras Cardiol. 2001;77:6976.

6. Colan SD. Uhl Anomaly. In: Keane JF, Lock JE, Fyler DC, editors. Nadas' Pediatric Cardiology. Philadelphia: Saunders; 2006. p. 444.
7. Gerlis LM, Schmidt-Ott SC, Ho SY, Anderson $\mathrm{RH}$. Dysplastic conditions of the right ventricular myocardium: Uhl's anomaly vs arrhytmogenic right ventricular dysplasia. Br Hearth J. 1993;69:142-50.

8. Cardarapoli D, Russo MG, Paladini D, Pisacane C, Caputo S, Giliberti P, et al. Prenatal echocardiography in a case of Uhl's anomaly. Ultrasound Obstet Gynecol. 2006;27:712-5.

9. Güler N, Demirbag R, Eryonucu B, Gül A. A case of successful six consecutive deliveries in a 41-yearold woman with Uhl's anomaly. International Journal of Cardiology. 2003;87:283-5.

10. Tanoue Y, Kado H, Shiokawa Y. Uhl's anomaly complicated with critical ventricular arrhythmia in a 2-month-old infant. European Journal of Cardiothoracic Surgery. 2003;24:1040-2.

11. Hoschtitzky A, Rowlands H, Ilina M, Khambadkone S, Elliott MJ. Single ventricle strategy for Uhl's anomaly of the right ventricle. Ann Thorac Surg 2010;90:2076-8. 